\title{
Injuries associated with falls from beds
}

\author{
D M Macgregor
}

\begin{abstract}
Objectives-To assess the severity of injuries due to falls from upper bunks and lower beds and cots, and to ascertain the age group most at risk of such injuries.

Setting-The accident and emergency (A\&E) department in the Royal Aberdeen Children's Hospital which has the only paediatric $A \& E$ department in the north east of Scotland, serving a catchment area of over half a million people.

Methods-All children attending with an injury sustained due to a fall from a bed or top bunk over five months had their case notes reviewed by the author.

Results-Eighty five children were identified, a majority of whom were reported to have fallen out of bed while sleeping. Twenty five sustained a fracture, 27 a head injury, 12 a laceration requiring treatment, and 21 sustained a soft tissue injury to a limb. Fourteen (16\%) required admission. Sixty six $(78 \%)$ of the injuries occurred in children under the age of 6 years.

Conclusion-These results show a higher incidence of significant injury than previously reported, and demonstrate the inadvisability of letting children under the age of 6 years sleep in upper bunks. In an attempt to make parents more aware of the risks it is recommended that these dangers should be brought to public attention.

(Injury Prevention 2000;6:291-292)
\end{abstract}

Emergency

Department, Royal

Aberdeen Children's

Hospital, Cornhill

Road, Aberdeen

AB25 2ZG, UK

Correspondence to:

Dr DM Macgregor

(dianamacgregor@yahoo.com)

Keywords: beds; falls

As children grow, the place in which they sleep is changed from a cot to a bed and sometimes to an upper bunk. The timing of this is dictated

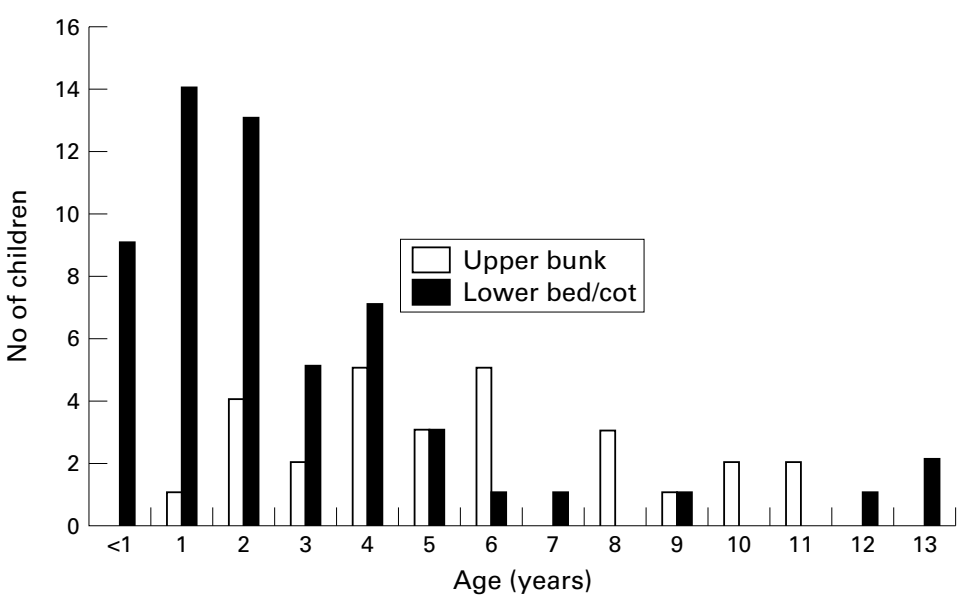

Figure 1 Upper bunk/lower bed injuries by age. new baby in the family. Changes may occur at an inappropriately young age if there are several younger siblings. Based on clinical encounters it seemed that most falls from upper bunks and beds occurred in young children and resulted in a higher proportion of significant injuries than previously shown. ${ }^{12}$ Accordingly the aim of this study was to try to confirm these suspicions and to suggest ways of reducing the morbidity associated with falls from upper bunks and beds.

\section{Methods}

An audit was undertaken over five months (January to May 1998), in the accident and emergency (A\&E) department of the Royal Aberdeen Children's Hospital. This hospital annually sees over 22000 new casualties under the age of 14 years. The attendance card of each child presenting with a bunk/bed/cot related injury was systematically reviewed and the type and severity of each injury noted. The possibility of non-accidental/intentional injury was considered in each of the presentations, but all the injuries were judged to be consistent with the history given.

\section{Results}

During the five month period 8343 new casualties were seen in the department. Eighty five cases $(1 \%)$ were identified as having sustained an injury after falling from an upper bunk/bed/ cot, most landing on a carpeted floor. There were 43 boys and 42 girls. Sixty six $(78 \%)$ of these were less than 6 years old (fig 1). Seventy two $(85 \%)$ ) fell while sleeping, 10 fell off a lower bunk/bed while bouncing or playing on the bed, and one fell while scaling the ladder to an upper bunk. Two of the upper bunk related injuries occurred when a child jumped off the bunk; the remainder happened to sleeping children. There were no instances of children getting trapped between the bars of a bunk bed. The three children who fell from a cot did so trying to scale the cot side. Eight children sustained an injury from hitting adjacent furniture during the fall.

Injuries sustained were categorised as fractures, head injuries, soft tissue injuries (sprains and haematomas), and lacerations and were noted according to age.

There were 25 fractures $(29 \%$ of children seen); 18 occurred in children under the age of 6 years, eight of which were as a result of a fall from a top bunk. Those due to falls from top bunks represented $4 \%$ of all fractures seen during this period and those due to top bunk falls in children under 6 years of age represented $2 \%$ of all fractures seen. They comprised eight supracondylar elbow fractures, seven fractures of the radius and/or ulna, five of 
Key points

- There is a high incidence of injuries sustained from falls from bunks and beds.

- $78 \%$ occurred in children under the age of 6 years.

- $52 \%$ sustained a significant injury.

- It is recommended that safety advice is included in all injury prevention material in order to increase public awareness of the potential for significant injury.

the clavicle, two coccyx fractures, one tibial fracture, and a buckle fracture of the femur in a 2 year old who bounced off the bed while playing. There was only one "bunk bed fracture" (impaction of the proximal first metatarsal, lateral cuneiform, and less often the medial cuneiform). ${ }^{3} \mathrm{~A}$ total of 27 children sustained a head injury, seven of whom had significant symptoms: loss of consciousness, vomiting, or drowsiness. There were no skull fractures and no cases of intracranial bleeding. The remainder had no neurological symptoms and were classed as having sustained a minor head injury. All these children made a full recovery. There were 12 lacerations, mostly of the scalp or face, one requiring admission for repair under a general anaesthetic. Twenty one children sustained a soft tissue injury to a limb.

Fourteen $(16 \%)$ of the children required admission. Seven were admitted to the A\&E ward for observation after a head injury and four to the orthopaedic ward for manipulation of a fracture under a general anaesthetic. One laceration required suturing under a general anaesthetic. Two children were admitted for drying of full leg plasters.

Forty four $(52 \%)$ of the children had an injury which was classified as "significant". This is higher than in previous studies. Eighty one per cent of the 45 significant injuries occurred in children under the age of 6 years, and 10 of these were due to a fall from an upper bunk. Of the remaining 41 less significant injuries, $33(80 \%)$ occurred in children under 6 years of age, five due to falls from an upper bunk.

\section{Discussion}

As in the USA, there are regulations in the UK requiring bunk beds to comply with the requirements of the UK Bunk Beds (Entrapment Hazards)(Safety Regulations 1987) and the European Standard EN 747-1. Most companies selling bunk beds recommend that children under 6 years of age should not be using top bunks.
In 1990 in the USA Selbst et al undertook a prospective study of the incidence, epidemiology, and outcome of injuries relating to bunk beds. ${ }^{4}$ They noted that there were more injuries associated with using top bunks than when using lower bunks/beds or scaling the ladder to a top bunk. They also showed that $70 \%$ occurred in children under the age of 6 yearssimilar to our figure of $78 \%$. Only $29 \%$ occurred while the children were asleep, whereas we found a much higher proportion $(85 \%)$. In the USA study, half of the presentations were head injuries and only $10 \%$ sustained fractures. Again, this differs from our study which showed $32 \%$ sustaining head injuries and $29 \%$ fractures. Nine per cent of the presentations in the USA were admitted to hospital as opposed to $16 \%$ in our study. However this may represent different admission policies.

We were unable to conclude that children under the age of 6 years are more likely to fall out of upper bunks as it was impossible to get figures for the presumably large numbers of children sleeping in upper bunks who do not fall out or injure themselves. However, despite the UK Safety Regulations and the standard recommendations concerning the safe age for children to use upper bunk beds, it would appear that parents are either unaware of this advice or it is ignored. It was also surprising to find so many children falling from lower bunks/beds and sustaining significant injuries. Perhaps the use of commercially available bed sides or appropriately placed pillows might reduce this risk. The findings of this study were presented to the Grampian Regional Home Safety Committee and a local publicity campaign is planned to provide advice on how to reduce the incidence of such injuries. We recommend that such advice be included in all injury prevention material to increase public awareness of the potential for significant injury when children under the age of 6 years sleep in upper bunks. It should also alert parents to the potential for injury resulting from falls from lower bunks/beds. It may be appropriate to advise parents not to place other furniture close to a bed/bunk in order to avoid injury during a fall. It would also seem prudent to discourage children from bouncing or jumping on beds.

1 Lyons TJ, Oates RK. Falling out of bed: a relatively benign occurrence. Pediatrics 1993;92:125-7.

2 Nimityongskul P, Anderson LD. The likelihood of injuries when children fall out of bed. F Pediatr Orthop 1987;7:1846.

3 Johnson GF. Pediatric Lisfranc injury: "bunkbed fracture". AFR 1981;137:1041-4.

4 Selbst SM, Baker MD, Shames M. Bunkbed injuries. Am F Dis Child 1990;144:721-3. 